\title{
Construção de indicadores de avaliação de processo de aprendizagem para um curso de enfermagem
}

\author{
Construction of evaluation indicators of the learning process for a nursing course
}

Construcción de indicadores de evaluación del proceso de aprendizaje para un curso de enfermería

Luzmarina Aparecida Doretto Braccialli ${ }^{1}$, Anete Maria Francisco ${ }^{2}$, Magali Aparecida Alves de Moraes ${ }^{3}$, Maria Helena Ribeiro de Carvalho ${ }^{4}$, Marilda Marques Luciano Marvulo ${ }^{5}$, Odilon Marques de Almeida Filho ${ }^{6}$

${ }^{1}$ Enfermeira, Doutora em Enfermagem. Docente da Faculdade de Medicina de Marília (FAMEMA). Marília, SP, Brasil. E-mail: luzbra@terra.com.br.

2 Bióloga, Doutora em Ecologia e Recursos Naturais. Docente da FAMEMA. Marília, SP, Brasil. E-mail: anetemf@gmail.com.

3 Psicóloga, Doutora em Educação. Docente da FAMEMA. Marília, SP, Brasil. E-mail: dmagalimoraes@hotmail.com.

${ }^{4}$ Enfermeira, Doutora em Biologia Oral. Docente da FAMEMA. Marília, SP, Brasil. E-mail: marihel2002@uol.com.br.

${ }^{5}$ Enfermeira, Mestre em Enfermagem Fundamental. Docente da FAMEMA. Marília, SP, Brasil. E-mail: mamaluma@famema.br.

${ }^{6}$ Farmacêutico - Bioquímico, Doutor em Ciências Biológicas. Docente da FAMEMA. Marília, SP, Brasil. E-mail: odilonbio@yahoo.com.br.

\section{RESUMO}

O objetivo foi construir indicadores de avaliação de processo para um curso de graduação de enfermagem. Conferência de Consenso, realizada por especialistas a partir de matriz inicial, contendo 209 indicadores em quatro áreas de competência do curso que, após três etapas de conferência, validaram os indicadores. A análise realizada com a média e o desvio padrão de cada indicador levou à matriz final que contemplou 87 indicadores. Os especialistas concordaram que todos os indicadores deveriam constar nas quatro séries do Curso de Enfermagem, considerando-se o grau de autonomia do estudante em cada série, por ser um currículo integrado e orientado por competência. Os indicadores poderão subsidiar gestores locais na avaliação de processo do Curso de Enfermagem, mas também são indicados a outros gestores de cursos da área da saúde que utilizem um currículo por competência e metodologias ativas de ensino e aprendizagem.

Descritores: Educação em Enfermagem; Conferência de Consenso; Educação Baseada em Competências.

\section{ABSTRACT}

The objective of this study was to build process assessment indicators for a nursing undergraduate course. The indicators were validated after three stages of a consensus conference, developed by experts based on an initial matrix with 209 indicators, in four areas of competence of the course. The analysis, performed with the mean and standard deviation of each indicator, led to the final matrix, comprising 87 indicators. The experts agreed that all indicators should be in the four stages of the nursing course program, considering the degree of autonomy of the undergraduate in each stage, and the fact that it is an integrated course, oriented by competences. The indicators may support local managers in the process assessment of the nursing course, as well as help other course managers in the health area use a program oriented by competences and active learning and teaching methodologies.

Descriptors: Education, Nursing; Consensus Development Conference; Competency-Based Education.

\section{RESUMEN}

Se objetivó construir indicadores de evaluación de proceso para un curso de grado de enfermería. Conferencia de Consenso, realizada por especialistas a partir de matriz inicial incluyendo 209 indicadores en cuatro áreas de competencia del curso, que luego de tres etapas de conferencia validaron los indicadores. El análisis realizado con el promedio y el desvío estándar de cada indicador determinó la matriz final, que contempló 87 indicadores. Los especialistas concordaron en que todos los indicadores deberían constar en las cuatro series del Curso de Enfermería, considerándose el grado de autonomía del estudiante en cada serie por ser un programa integrado y orientado por competencia. Los indicadores podrán ayudar a administradores locales en la evaluación de proceso del Curso de Enfermería, y también ofrecerlo a otros gestores de cursos del área de salud que utilicen un programa por competencia y metodologías activas de enseñanza y aprendizaje.

Descriptores: Educación en Enfermería; Conferencia de Consenso; Educación Basada en Competencias. 


\section{INTRODUÇÃo}

A Faculdade de Medicina de Marília - Famema nos seus quase 50 anos de existência vem trabalhando na transformação permanente dos currículos dos Cursos de Medicina e Enfermagem visando à integração básico clinica e a utilização de métodos ativos de ensino e aprendizagem. Seu pioneirismo vem contribuindo com a produção científica nacional e internacional, assim como, com as mudanças curriculares em outras instituições de ensino na área da saúde ${ }^{(1-4)}$.

Assim, embora a Famema tenha monitorado o processo das mudanças curriculares em consonância com as Diretrizes Curriculares Nacionais $(\mathrm{DCN})^{(5)}$ que orienta o profissional a ser formado e se desenvolvendo no processo avaliativo nos diferentes cenários de ensinoaprendizagem, ainda não dispõe de indicadores que possam avaliar, de uma forma global, o processo de formação dos estudantes.

Diante da necessidade de pensar nesses indicadores e, tendo em vista a experiência do seu corpo docente no uso de metodologias ativas, foi proposta essa pesquisa pela importante possibilidade de consolidação da mesma de forma participativa, propiciando a contribuição dos profissionais com a construção de indicadores. Reconhece-se a superioridade do juízo de pessoas experientes em relação ao individual ou mesmo de um pequeno grupo $^{(6)}$. Deve-se destacar que, na literatura, encontram-se vários trabalhos sobre o desenvolvimento de avaliação de produto, no entanto, identifica-se uma escassez de estudos abordando a avaliação de processo em relação às mudanças na formação de profissionais de saúde ${ }^{(7-8)}$.

O Curso de Enfermagem da Famema está organizado, desde 2003, por currículo integrado e orientado por competência dialógica, utilizando metodologias ativas nas suas Unidades Educacionais. Segundo o projeto pedagógico do curso, a aprendizagem é "orientada para a ação e a avaliação da competência é baseada nos processos e resultados observáveis, denominados desempenhos que, por sua vez, compõem-se de atributos (habilidades e capacidades) que se desenvolverão ao longo das séries do curso"(1).

Os atributos são afetivos, cognitivos e psicomotores, ou seja, saberes, as capacidades, as informações, relações interpessoais, valores e crenças, atitudes, princípios bioéticos, destrezas e habilidades para solucionar eficazmente os problemas da prática profissional $^{(9)}$.

Nesse sentido, a avaliação do desempenho dos estudantes não pode ser considerada um check list, mas sim uma ação que envolve a articulação de tarefas e atributos de maneira ampliada. A avaliação possibilita a ação, a reflexão e uma nova ação favorecendo o desenvolvimento da aprendizagem em um contexto da prática profissional ${ }^{(10)}$.

Dessa forma, a elaboração de Indicadores para o Curso de Enfermagem implica em considerar o currículo nos quatro anos e em identificar a terminalidade de cada série, de acordo com sua complexidade. Esse processo e os resultados advindos da análise de indicadores poderá auxiliar o aprimoramento do processo de formação do enfermeiro, de forma o mais articulada possível, podendo apresentar também a comunidade cientifica uma possibilidade para a condução desse processo em outras Instituições de Ensino Superior (IES).

A literatura recomenda que o uso de indicadores de avaliação podem auxiliar gestores, permitindo que estes operem sobre "as dimensões-chave de sistemas e de processo, monitorando situações que devem ser mudadas, incentivadas ou potencializadas desde o início de uma intervenção até o alcance do que foi pretendido e previsto como resultado"(6), possibilitando assim implementar as alterações curriculares que se fizerem necessárias.

Um dos conceitos de indicador é que este é "um significante que testemunha a existência de um determinado fenômeno. É um signo que nos faz reconhecer a presença de um efeito previsto"(11). Os indicadores podem "servir de guia para o estudante saber o que dele se espera em termos de processos e resultados de aprendizagem e expressa uma probabilidade, uma hipótese de alcance dos critérios, nunca uma certeza"(12). Outra autora acrescenta que sua função é apenas ser um sinalizador: indicadores são instrumentos, não operam por si mesmos, indicam o que devem indicar ${ }^{(6)}$.

Os indicadores podem ser referidos ainda aos aspectos tangíveis e intangíveis da realidade. Tangíveis são os elementos facilmente observáveis, como dados de identificação, exame físico e outros. Intangíveis são os atributos que só podem ser captados indiretamente por meio de suas formas de manifestação, como é o caso de valores, da autoestima, de atitudes e outros ${ }^{(6)}$.

A partir dos argumentos elaborados no texto, desenvolveu-se o presente estudo partindo da seguinte questão de pesquisa: quais são os indicadores de um curso de enfermagem por série?

Assim, propõem-se como objetivo da pesquisa construir indicadores de avaliação de processo para um curso de graduação de enfermagem. 


\section{MÉTODO}

Pesquisa descritiva de cunho qualitativo ${ }^{(13)}$, realizada entre dezembro de 2010 a dezembro de 2011, que utilizou a conferência de consenso ${ }^{(14)}$, que consiste em uma técnica mista que concilia uma discussão ampla e aberta entre especialistas no sentido de buscar um consenso e, ao mesmo tempo, preservar o anonimato.

O estudo foi conduzido por pesquisadores pertencentes ao grupo de avaliação da Famema. Este era constituído de sete docentes de diferentes áreas profissionais, sendo: médico, enfermeiro docente e assistencial, farmacêutico, bióloga e psicóloga. Estes elaboraram uma matriz inicial com 209 indicadores distribuídos entre as quatro áreas de competência (cuidado das necessidades individuais em todas as fases do ciclo de vida; cuidado das necessidades coletivas em saúde; organização e gestão do processo de trabalho em saúde e iniciação científica), considerando a especificidade para cada série. Os indicadores foram construídos tendo como referencial o Projeto Político do Curso de Enfermagem e a proposta pedagógica das unidades educacionais de cada série do curso de Enfermagem para o ano de 2010.

Para composição do grupo de especialistas, foram convidados para participar da conferência de consenso quatro professores da Famema e dois externos, de outras Instituições de Ensino Superior. A técnica utilizada preconiza que os participantes da conferência tenham competência adequada para análise da proposta em discussão. Assim, foram considerados critérios para inclusão desse grupo na pesquisa, profissionais enfermeiros com expertise em currículos de cursos com metodologias ativas e profissionais com vivência no acompanhamento da prática de estudantes em diversos cenários de ensino e aprendizagem, tais como enfermeiros assistenciais, gestores, preceptores e docentes. Os especialistas foram identificados por sua expertise, convidados e confirmaram a sua participação na pesquisa após recebimento da carta convite.

\section{Etapas da conferência}

A primeira etapa consistiu em atribuir pontuação à matriz inicialmente elaborada. A matriz inicial foi encaminhada via correio postal e eletrônico aos especialistas com prazo de 60 dias para devolução do material.

Os especialistas atribuíram a cada indicador da matriz inicial uma pontuação de zero a 10, de acordo com o grau de importância de cada indicador no currículo, podendo ainda sugerir a inclusão de novos indicadores ou alteração dos mesmos. A nota 10 significou a de maior importância ao indicador. Por outro lado, a nota zero significou que o indicador deveria ser excluído, orientações encaminhadas aos especialistas.

Todas as matrizes retornaram preenchidas para o grupo de pesquisadores que consolidou as respostas, por meio de média aritmética e do desvio padrão, significando o grau de importância e o grau de consenso de cada indicador, respectivamente. Assim, quanto maior a média, maior a importância do indicador e quanto menor o desvio padrão, maior o grau de consenso, independentemente da importância conferida ao indicador. Nessa etapa, foram mantidos todos os indicadores, a despeito dos valores atribuídos, recebendo a denominação de matriz consolidada.

A segunda etapa da conferência realizou-se com a presença dos especialistas em um grupo de discussão, coordenado por um dos pesquisadores. Todos os que preencheram a matriz estiveram presentes. 0 coordenador apresentava ao grupo 0 indicador consolidado por área de competência, assim como a média e o desvio padrão, preservando o anonimato dos participantes. Durante oito horas, os especialistas debateram sobre os indicadores, visando esclarecer cada um deles, sem necessariamente, chegarem a um consenso. Os demais pesquisadores acompanharam a discussão, participando apenas com anotações das sugestões dos especialistas para a nova matriz. Além disso, a conferência foi filmada, após a autorização dos mesmos. Durante toda a discussão, os especialistas apresentaram visões divergentes e convergentes, sendo todas acolhidas para a construção de uma nova matriz.

Na terceira etapa da conferência, foi enviada ao grupo de especialistas a nova matriz contendo, agora, após a reunião presencial, 91 indicadores para nova pontuação, com um prazo estipulado de um mês para a sua devolução.

Após o recebimento da nova matriz, os pesquisadores realizaram um novo tratamento estatístico, com média e desvio padrão. Com base na Conferência de Consenso(14), foram estabelecidos os seguintes pontos de corte:

Todo o indicador com média maior ou igual a sete foi considerado importante. Inferior a esse valor, foi considerado pouco importante, não devendo fazer parte da matriz de indicadores do currículo.

Todo indicador com desvio padrão inferior a três foi considerado consensual.

Os indicadores com média igual ou superior a sete e desvio padrão igual ou superior a três foram excluídos porque não foram consensuais. 
Desse modo, todos os indicadores foram considerados importantes, excluindo-se quatro não consensuais da matriz de indicadores.

O projeto de pesquisa foi aprovado pelo Comitê de Ética em Pesquisa da Famema sob o protocolo no 774/10. Os sujeitos que participaram desta, assinaram Termo de Consentimento Livre e Esclarecido, em que se salientou que a pesquisa não possibilitava riscos e benefícios, ficando, os mesmos, livres para se desligarem dela, em qualquer momento que o desejassem.

\section{RESULTADOS}

Após a conferência, houve consenso que a matriz inicial fosse re-elaborada, excluindo-se 122 indicadores dos 209 inicialmente propostos, resultando, assim em 87 indicadores para avaliação das quatro áreas de competência: cuidado das necessidades individuais em todas as fases do ciclo de vida; cuidado das necessidades coletivas em saúde; organização e gestão do processo de trabalho em saúde e iniciação científica.

Da matriz inicial com 109 indicadores da área de competência - Necessidades de Saúde Individual - 68 foram eliminados pelos especialistas após a conferência de consenso, restando 41 (Quadro 1). Nas discussões entre os especialistas, foi consenso que o exame físico não necessitava de detalhamento na matriz de indicadores, por ser validado internacionalmente.
Do quadro inicial com 57 indicadores da área de competência - Necessidades Coletivas em Saúde - 48 foram eliminados pelos especialistas após a conferência de consenso, restando nove (Quadro 2). Alguns indicadores dessa área foram deslocados para outras áreas de competência e, ainda outros, foram eliminados e/ou agrupados seguindo a mesma justificativa da área anterior.

Dos 24 indicadores propostos para a área de competência - Organização e Gestão do Processo de Trabalho em Saúde - seis foram eliminados pelos especialistas (Quadro 3).

A eliminação de alguns indicadores dessas três áreas deve-se ao fato de seu excessivo detalhamento, o que acarretaria um possível distanciamento do desempenho proposto. Outros foram agrupados por apresentarem o mesmo contexto.

$\mathrm{Na}$ área de competência - Iniciação Científica - a matriz inicial continha 19 indicadores e todos foram mantidos (Quadro 4).

Os especialistas consensuaram que todos os indicadores deveriam constar nas quatro séries do Curso de Enfermagem, considerando o grau de autonomia do estudante em cada série, em um currículo integrado por competência.

Quadro 1: Indicadores da área de competência: cuidado das necessidades individuais. Marília, SP, Brasil, 2011.

\begin{tabular}{|c|c|c|c|c|}
\hline \multicolumn{5}{|c|}{$\begin{array}{c}\text { Área de vigilância à saúde: cuidado das necessidades individuais em todas as fases do ciclo de vida } \\
\text { Desempenho: IDENTIFICA NECESSIDADES DE SAÚDE }\end{array}$} \\
\hline Ação: História Clínica & $\begin{array}{l}\text { Ação: Exame } \\
\text { Clínico Geral }\end{array}$ & $\begin{array}{l}\text { Ação: Exame } \\
\text { Físico Específico }\end{array}$ & $\begin{array}{l}\text { Ação: Raciocínio } \\
\text { Clínico }\end{array}$ & $\begin{array}{c}\text { Ação: } \\
\text { Investigação } \\
\text { Diagnóstica }\end{array}$ \\
\hline \multicolumn{5}{|l|}{ No atendimento e/ou no relato: } \\
\hline $\begin{array}{l}\text { 1. Apresenta-se de forma a clarear } \\
\text { sua identificação, obtém o } \\
\text { consentimento da pessoa ou } \\
\text { responsável e assegura o sigilo; }\end{array}$ & $\begin{array}{l}\text { 13. Obtém o } \\
\text { consentimento } \\
\text { para proceder } \\
\text { ao exame físico } \\
\text { e orienta sobre } \\
\text { os } \\
\text { procedimentos } \\
\text { a serem } \\
\text { realizados; }\end{array}$ & $\begin{array}{l}\text { 16. Demonstra } \\
\text { habilidade e } \\
\text { técnica } \\
\text { adequadas de } \\
\text { inspeção, } \\
\text { palpação, } \\
\text { percussão e } \\
\text { ausculta de } \\
\text { acordo com cada } \\
\text { sistema do } \\
\text { organismo; }\end{array}$ & $\begin{array}{l}\text { 18. Integra e organiza } \\
\text { os dados obtidos a } \\
\text { partir da coleta de } \\
\text { dados, visando à } \\
\text { formulação do problema } \\
\text { da pessoa, } \\
\text { considerando o } \\
\text { contexto, condições de } \\
\text { vida e trabalho das } \\
\text { pessoas; }\end{array}$ & $\begin{array}{l}\text { 24. Justifica } \\
\text { suas decisões, } \\
\text { com princípios } \\
\text { éticos, } \\
\text { raciocínio } \\
\text { clínico e } \\
\text { epidemiológico; }\end{array}$ \\
\hline $\begin{array}{l}\text { 2. Adota postura acolhedora e atitude } \\
\text { ética que favoreçam o vínculo, do } \\
\text { início ao final do contato. Tem } \\
\text { percepção e sensibilidade para adotar } \\
\text { a melhor estratégia acolhedora no } \\
\text { momento do cuidado, no sentido de } \\
\text { se observar a criação do vínculo } \\
\text { afetivo; }\end{array}$ & $\begin{array}{l}\text { 14. Adota } \\
\text { medidas } \\
\text { ergonômicas e } \\
\text { de } \\
\text { biossegurança, } \\
\text { considerando } \\
\text { as Normas de } \\
\text { Regulamentaçã } \\
\text { o vigente (NR- } \\
32 \text {; }\end{array}$ & $\begin{array}{l}\text { 17. Encaminha } \\
\text { alternativas na } \\
\text { dificuldade de } \\
\text { conclusão do } \\
\text { exame. }\end{array}$ & $\begin{array}{l}\text { 19. Formula o problema } \\
\text { de saúde da pessoa a } \\
\text { partir das necessidades } \\
\text { de saúde; }\end{array}$ & $\begin{array}{l}\text { 25. Considera a } \\
\text { relação } \\
\text { custo/efetividad } \\
\text { e, o acesso e o } \\
\text { financiamento } \\
\text { dos recursos; }\end{array}$ \\
\hline
\end{tabular}




\begin{tabular}{|c|c|c|c|}
\hline $\begin{array}{l}\text { 3. Aplica princípios de biossegurança } \\
\text { segundo protocolo da ANVISA, } \\
\text { respeitando as Normas de } \\
\text { Regulamentação vigente; }\end{array}$ & $\begin{array}{l}\text { 15. Realiza } \\
\text { exame clinico } \\
\text { geral } \\
\text { considerando } \\
\text { as diferentes } \\
\text { fases do ciclo } \\
\text { de vida e } \\
\text { segundo } \\
\text { princípios } \\
\text { éticos. }\end{array}$ & $\begin{array}{l}\text { 20. Elabora rede } \\
\text { explicativa do problema } \\
\text { a partir das } \\
\text { necessidades de saúde; }\end{array}$ & $\begin{array}{l}\text { 26. Solicita e } \\
\text { interpreta } \\
\text { recursos } \\
\text { complementare } \\
\text { s para } \\
\text { confirmar ou } \\
\text { afastar as } \\
\text { hipóteses e } \\
\text { intervém } \\
\text { quando } \\
\text { necessário. }\end{array}$ \\
\hline $\begin{array}{l}\text { 4. Identifica situações em que a } \\
\text { pessoa está impossibilitada de } \\
\text { atender o estudante. Respeita e } \\
\text { define estratégia; }\end{array}$ & & $\begin{array}{l}\text { 21. Identifica os } \\
\text { recursos disponíveis } \\
\text { para os problemas } \\
\text { frente a sua explicação; }\end{array}$ & \\
\hline $\begin{array}{l}\text { 5. Identifica situações que impeçam a } \\
\text { realização da história clínica e realiza } \\
\text { ações pertinentes de acordo com o } \\
\text { grau de autonomia do estudante; }\end{array}$ & & $\begin{array}{l}\text { 22. Identifica os riscos } \\
\text { do indivíduo para } \\
\text { propor plano de ação; }\end{array}$ & \\
\hline $\begin{array}{l}\text { 6. Realiza entrevista com ritmo } \\
\text { adequado ao tempo disponível em } \\
\text { cada cenário; }\end{array}$ & & $\begin{array}{l}\text { 23. Informa suas } \\
\text { hipóteses e a } \\
\text { investigação necessária } \\
\text { para os problemas, de } \\
\text { forma ética, empática e } \\
\text { compreensível à } \\
\text { pessoa/acompanhante. }\end{array}$ & \\
\hline \multicolumn{4}{|l|}{$\begin{array}{l}\text { 7. Identifica a pessoa, o informante e } \\
\text { os membros da família: nome } \\
\text { completo, idade, sexo, etnia, } \\
\text { naturalidade, procedência atual e } \\
\text { remota, profissão, atividade que } \\
\text { exerce ou exercia, religião, estado } \\
\text { civil e escolaridade e o contexto } \\
\text { familiar no qual está inserido; }\end{array}$} \\
\hline \multicolumn{4}{|l|}{$\begin{array}{l}\text { 8. Observa a comunicação verbal e } \\
\text { não verbal considerando a autonomia } \\
\text { da pessoa; }\end{array}$} \\
\hline \multicolumn{4}{|l|}{$\begin{array}{l}\text { 9. Identifica a necessidade de utilizar } \\
\text { as ferramentas das tecnologias leve e } \\
\text { leve-dura; }\end{array}$} \\
\hline \multicolumn{4}{|l|}{$\begin{array}{l}\text { 10. Coleta dados considerando as } \\
\text { necessidades de saúde (boas } \\
\text { condições de vida, acesso à } \\
\text { tecnologia, vínculo, afeto e } \\
\text { autonomia); }\end{array}$} \\
\hline \multicolumn{4}{|l|}{$\begin{array}{l}\text { 11. Identifica e correlaciona aspectos } \\
\text { socioculturais contextualizando os } \\
\text { cenários; }\end{array}$} \\
\hline \multicolumn{4}{|c|}{\begin{tabular}{l|l} 
12. Registra a informação de forma & \\
clara e legível, sistematizada e & \\
articulada nos documentos & \\
pertinentes.
\end{tabular}} \\
\hline \multicolumn{4}{|c|}{ Desempenho: ELABORA, EXECUTA E AVALIA O PLANO DE CUIDADO } \\
\hline \multicolumn{4}{|c|}{ Ação: Plano de Cuidado } \\
\hline $\begin{array}{l}\text { 27. Participa da elaboração de planos } \\
\text { de cuidado com a } \\
\text { equipe/indivíduo/família, } \\
\text { contemplando ações de saúde } \\
\text { (promoção, prevenção, recuperação e } \\
\text { reabilitação) de acordo com a } \\
\text { explicação do problema identificado, } \\
\text { pautando-se em princípios éticos, } \\
\text { raciocínio clínico e epidemiológico; }\end{array}$ & & & \\
\hline
\end{tabular}




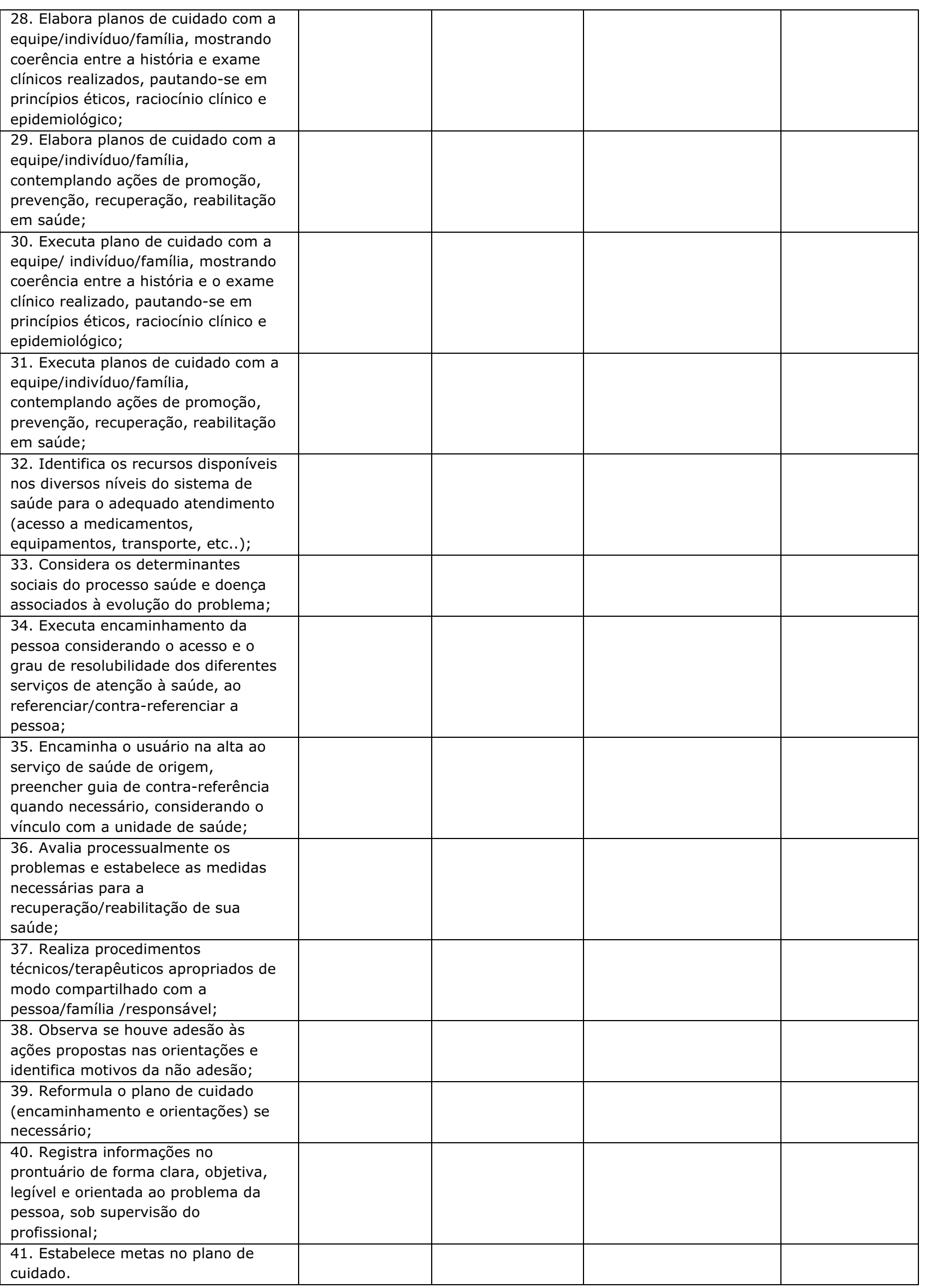


Quadro 2: Indicadores da área de competência: cuidado das necessidades coletivas em saúde. Marília, SP, Brasil, 2011.

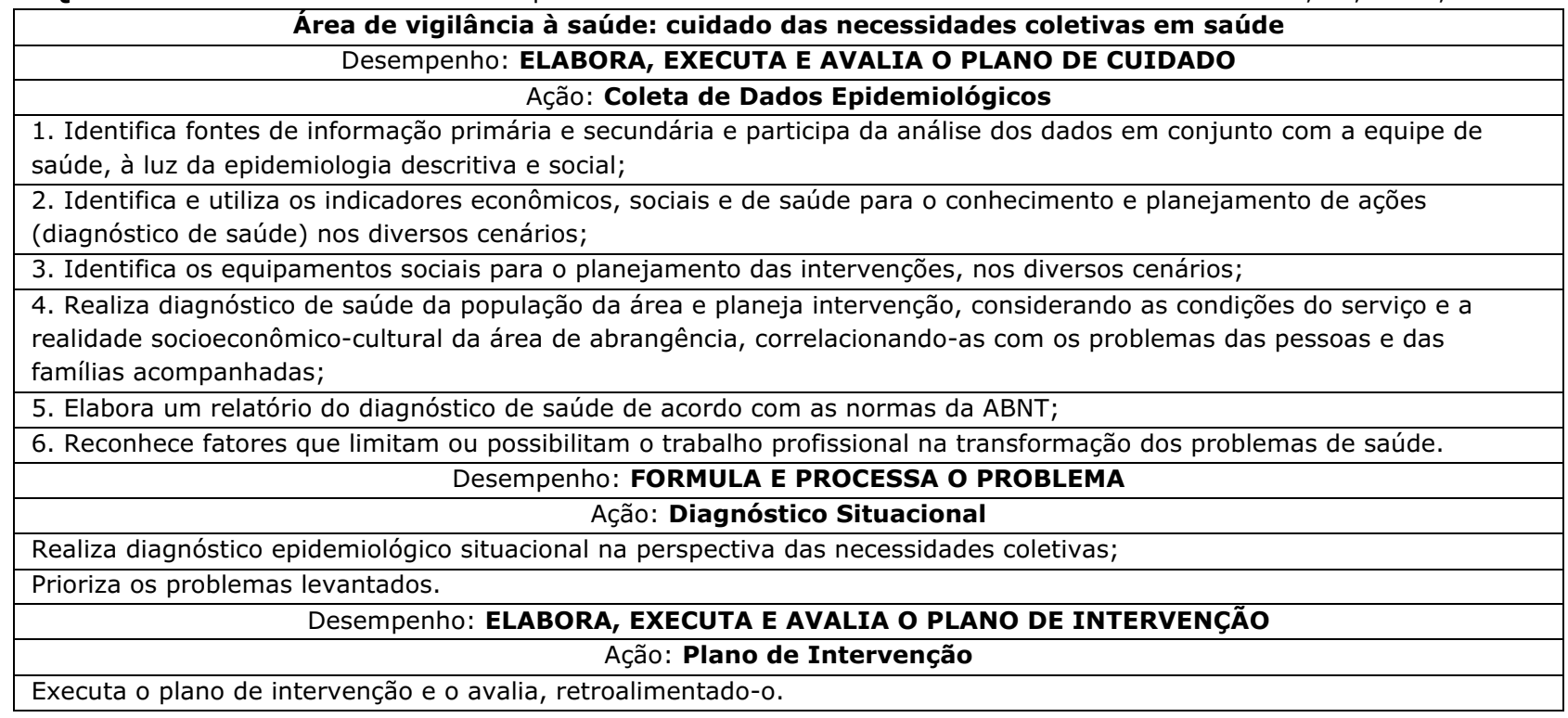

Quadro 3: Indicadores da área de competência: organização e gestão do processo de trabalho em saúde. Marília, SP, Brasil, 2011.

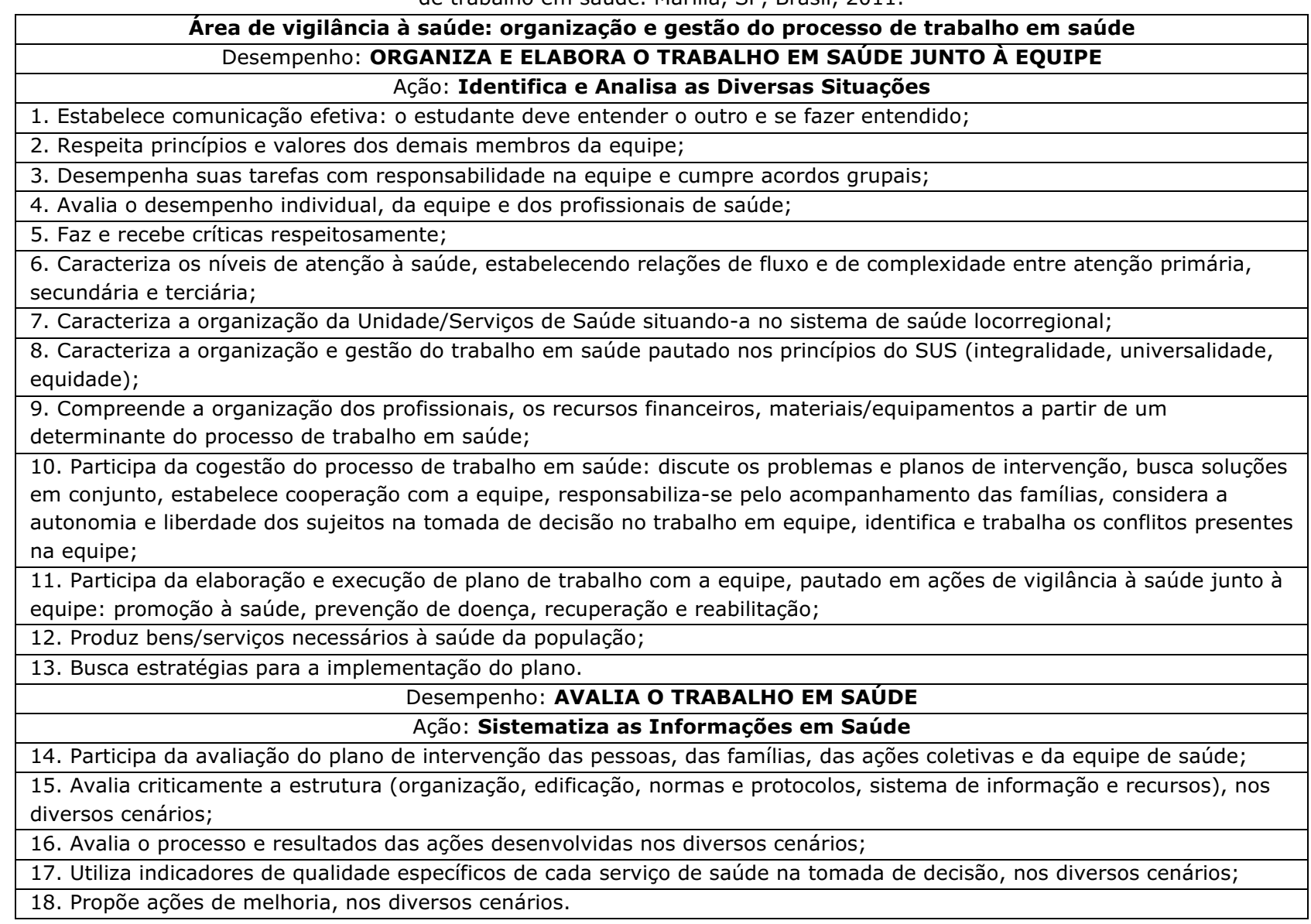


Quadro 4: Indicadores da área de competência: iniciação cientifica Marília, SP, Brasil, 2011.

\begin{tabular}{|c|c|c|}
\hline \multicolumn{3}{|c|}{ Área de vigilância à saúde: iniciação científica } \\
\hline \multicolumn{3}{|c|}{ Desempenho: IDENTIFICA E EXECUTA A PESQUISA } \\
\hline $\begin{array}{c}\text { Ação: Escolhe a Área e Delimita o } \\
\text { Tema }\end{array}$ & $\begin{array}{l}\text { Ação: Formula o Projeto } \\
\text { de Pesquisa: Introdução } \\
\text { - Objetivo - Método }\end{array}$ & $\begin{array}{c}\text { Ação: Executa o Projeto: Coleta e Analisa os } \\
\text { Dados; Interpreta Criticamente os } \\
\text { Resultados; Redige e Divulga a Pesquisa }\end{array}$ \\
\hline $\begin{array}{l}\text { 1. Compreende a pesquisa como uma } \\
\text { forma de propiciar a análise de um tema } \\
\text { sob novo enfoque ou abordagem; }\end{array}$ & $\begin{array}{l}\text { 4. Formula a pergunta da } \\
\text { pesquisa; }\end{array}$ & $\begin{array}{l}\text { 13.Identifica de maneira sistemática o material } \\
\text { coletado; }\end{array}$ \\
\hline $\begin{array}{l}\text { 2. Considera a relevância teórico-prática } \\
\text { e a disponibilidade de material } \\
\text { bibliográfico ao escolher o tema; }\end{array}$ & 5. Define sua delimitação; & $\begin{array}{l}\text { 14. Realiza as técnicas escolhidas para coleta de } \\
\text { dados; }\end{array}$ \\
\hline \multirow{7}{*}{$\begin{array}{l}\text { 3. Busca respostas para questões } \\
\text { propostas com sistematização e critérios } \\
\text { científicos. }\end{array}$} & 6. Define relevância; & 15. Interpreta os dados coletados; \\
\hline & 7. Elabora justificativa; & $\begin{array}{l}\text { 16. Discute os resultados, confrontando-os com } \\
\text { as referências bibliográficas; }\end{array}$ \\
\hline & 8. Define objetivos; & $\begin{array}{l}\text { 17. Elabora a redação final, de acordo com o } \\
\text { desenho metodológico do projeto de pesquisa; }\end{array}$ \\
\hline & $\begin{array}{l}\text { 9. Discute as estratégias de } \\
\text { busca; }\end{array}$ & $\begin{array}{l}\text { 18. Utiliza as normas técnicas de referências } \\
\text { bibliográficas, de acordo com a Associação } \\
\text { Brasileira de Normas Técnicas } \\
\text { (ABNT)/Vancouver; }\end{array}$ \\
\hline & $\begin{array}{l}\text { 10. Caracteriza o conjunto } \\
\text { do acervo bibliográfico a } \\
\text { ser consultado; }\end{array}$ & $\begin{array}{l}\text { 19. Apresenta os resultados da pesquisa em } \\
\text { eventos científicos/publicações. }\end{array}$ \\
\hline & $\begin{array}{l}\text { 11. Analisa criticamente as } \\
\text { fontes bibliográficas; }\end{array}$ & \\
\hline & $\begin{array}{l}\text { 12. Explica os } \\
\text { procedimentos } \\
\text { metodológicos. }\end{array}$ & \\
\hline
\end{tabular}

\section{DISCUSSÃO}

Os indicadores consensuados pelos enfermeiros e profissionais expertises em currículos com metodologias ativas apontam saberes fundamentais para a formação do enfermeiro, considerando as $\mathrm{DCN}^{(1)}$. Estes se referem aos saberes da ética/bioética, acolhimento, autonomia, vínculo, comunicação, medidas de biossegurança, processo grupal, relação profissional-paciente, políticas públicas de saúde, processo saúde e doença, entre outros.

Além destes, para o cuidado às necessidades individuais acrescenta-se a elaboração da história clínica, realização do exame físico geral e específico, desenvolvimento do raciocínio clínico, investigação diagnóstica, plano de cuidados e avaliação.

Em relação ao cuidado às necessidades coletivas em saúde os indicadores se referem à coleta de dados epidemiológicos, diagnóstico situacional e plano de intervenção.

Essas abordagens reforçam que os indicadores elencados pelos expertises subsidiam o acompanhamento do processo de ensino e aprendizagem dos estudantes no desenvolvimento do currículo para o cuidado. Este deve considerar o sujeito na sua singularidade e no coletivo, com valores, desejos, expectativas, crenças, autonomia, considerando a clínica e a epidemiologia, numa perspectiva do cuidado ampliado em saúde ${ }^{(15-16)}$.
Na área de vigilância à saúde: organização e gestão do processo de trabalho em saúde, os expertises consensuaram os indicadores referentes à organização, elaboração e avaliação do trabalho em saúde.

Em contrapartida, na graduação de enfermagem, a maioria dos currículos a formação é incipiente nesta área, a qual se mostra com modelos conservadores, fragmentados e com uso de tecnologias dura evidenciando que o foco do cuidado permanece na doença. Assim, reproduz as práticas e organização do trabalho quando deveria estruturar-se a partir da problematização da prática profissional e das necessidades de saúde das pessoas e da população ${ }^{(17-18)}$.

Finalmente, na área de iniciação científica os expertises reforçam todas as etapas de uma pesquisa científica. Esta possibilita o aprender a aprender, preconizado nas $\mathrm{DCN}^{(1)}$ e nos currículos com métodos ativos de ensino e aprendizagem e a construção do conhecimento com base no mundo do trabalho.

Os indicadores consensuados pelos expertises sustentam a proposta educacional da Famema, a qual parte do mundo do trabalho, a luz das $\mathrm{DCN}^{(5)}$ e do Sistema Único de Saúde, tendo em vista os saberes necessários do enfermeiro, frente a complexidade da educação, da gestão e da cidadania $^{(4)}$. 


\section{CONSIDERAÇÕES FINAIS}

Esta pesquisa contribuiu na elaboração de indicadores para um curso de enfermagem subsidiando a avaliação no processo ensino e aprendizagem nas áreas individuais, coletiva, gestão e iniciação científica.

A partir dos resultados desta pesquisa é possível desenvolver novos estudos que contemplem os indicadores especificando o grau de autonomia e complexidade em cada série em um currículo integrado

\section{REFERÊNCIAS}

1. Faculdade de Medicina de Marília. Projeto pedagógico do Curso de Enfermagem. Marília (SP): Faculdade de Medicina de Marília; 2008.

2. Faculdade de Medicina de Marília. Projeto pedagógico do Curso de Medicina. Marília (SP): Faculdade de Medicina de Marília; 2014.

3. Moraes MAA, Tonhom SFR, Hafner MLMB, Gomes R (orgs). Avaliação nos Cursos de Medicina e Enfermagem: desafios e perspectivas. Curitiba: CRV; 2012.

4. Higa EFR, Hafner MLMB, Tonhom SFR, Taipeiro EF, Moreira HM, Guimarães APC, Pinheiro OL. Indicadores de avaliação em gestão e saúde coletiva na formação médica. Rev. Brasileira de Educação Médica. 2013; 37(1): 52-9.

5. Brasil. Ministério da Educação. Conselho Nacional de Educação. Câmara de Educação Superior. Parecer CNE/CES no. 1133 de 7 agosto de 2001. Institui as diretrizes curriculares nacionais dos cursos de graduação em enfermagem, medicina e nutrição. Diário Oficial da União. Brasília, 3 out. 2001. [acesso em 6 jun 2014]. Disponível em:

http://www.mec.gov.br/Sesu/diretriz.shtm\#legislação.

6. Minayo MCS. Construção de indicadores qualitativos para avaliação de mudanças. Rev Bras Educ Med. 2009;33(supl 1):8391.

7. Braccialli LAD, Marvulo MML, Gomes R, Moraes MAA, Almeida Filho OM, Pinheiro OL, Hafner, MLMB. Cuidado ampliado em enfermagem. REME Rev Min Enferm. 2009;13(3):391-8.

8. Hafner MLMB, Moraes MAA, Marvulo MML, Braccialli LAD, Carvalho MHR, Gomes R. A formação médica e a clínica ampliada: resultados de uma experiência brasileira. Ciênc Saúde Coletiva. 2010;15(supl 1):1.715-24.

9. Braccialli LAD, Oliveira MAC de. Concepções de avaliação de desempenho em um currículo orientado por competência. Rev. Esc. Enfermagem USP. 2011; 45(5):1221-8.

10. Laluna MCC, Ferraz CA. Os sentidos da prática avaliativa na formação de enfermeiros. Rev. Lat am Enfermagem. 2009; 17(1):21-7.

11. Hadji C. A avaliação: regras do jogo, das intenções aos instrumentos. Porto: Porto Editora; 1994.

12. Depresbiteris L. Avaliação da aprendizagem: casos comentados. Pinhais (PR): Melo; 2011. Critérios e indicadores de avaliação; p. 63-74.

13. Hernández Sampieri R, Fernández Collado C, Baptista Lucio MP. Metodologia de pesquisa. $5^{a}$ ed. Porto Alegre (RS): Penso; 2013.

14. Fernandes LEP, Vieira-da-Silva LM, Hartz ZMA. Conferência de consenso sobre a imagem-objetivo da descentralização da atenção à saúde no Brasil. In: Hartz ZMA, Vieira-da-Silva LM, organizadores. Avaliação em saúde: dos modelos teóricos à prática na avaliação de programas e sistemas de saúde. Salvador (BA): EDUFBA; 2005. p. 65-102.

15. Assis MMA, et al (Org.) Produção do cuidado no programa de saúde da família: olhares analisadores em diferentes cenários. Salvador: EDUFBA, 2010. 180p.

16. Braccialli LAD, Oliveira MAC. Desafios na formação médica: a contribuição da avaliação. Rev. Brasileira de Educação Médica. Rio de Janeiro. 2012; 36(2):280-8. orientado por competência dialógica. Esses podem ser elaborados a partir do monitoramento do processo de avaliação proposto.

Os indicadores poderão subsidiar gestores locais na avaliação de processo do Curso de Enfermagem, como também gestores de outros cursos da área da saúde que utilizem um currículo integrado por competência dialógica e metodologias ativas de ensino e aprendizagem.

17. Ceccim RB, Fuerwerker, LCM. O quadrilátero da formação para a área da saúde: ensino, gestão, atenção e controle social. Rev. Saúde Coletiva 2004; 14(1):41-65.

18. Campos GWS, Minayo MCS, Akerman M, Drumond Junior M, Carvalho YM (orgs.) Tratado de Saúde Coletiva. São Paulo: Hucitec; Rio de Janeiro: Fiocruz; 2006.

Artigo recebido em 07/03/2013.

Aprovado para publicação em 05/06/2014.

Artigo publicado em 31/03/2015. 